\title{
Intensification-induced Degradation of Irrigated Infrastructure: The Case of Waterlogging and Salinity in Pakistan
}

\author{
USMan Mustafa and P. L. PINGali
}

\section{INTRODUCTION}

Water and land development, use, and distribution has played a vital role in agricultural development in Pakistan. The country's canal irrigation system is the largest contiguous irrigation system in the world-consisting of 40,000 miles of canals and over 80,000 water courses, field channels and ditches running for another million miles [Qureshi and Zakir (1994)]. This irrigation network covers more than 70 percent of Pakistan's agriculture.

Private investment has also contributed significantly to the irrigation system in the form of private tubewells. About 32 percent of farm-gate available water is supplied by the private tubewells, [Government of Pakistan (1988)]. These developments have not only brought new land under cultivation but also permitted a considerable increase in cropping intensities.

\section{Declining Public Irrigation Investment and the Degradation of Irrigation Infrastructure}

There was, initially, a large but declining public investment in agriculture and irrigation infrastructure in Pakistan. Out of 9.5 percent of the total development expenditure in the 1955-60 period, the allocation to agriculture dropped to 3.5 percent in the 1986-93 period [Government of Pakistan (1993)]. Massive resource transfers have occurred out of the agriculture sector during the past. From 1980-81 to 1989-90 alone the net amount transferred out of agriculture was Rs 156 billion. There are complex mechanisms involved in causing these transfers; these include direct taxes, implicit taxes, subsidies to industry and consumers, and foreign exchange rate misalignment [John Mellor Associate (1993)]

Despite the huge initial capital investment on irrigation development, however, the performance of most irrigation systems is not satisfactory. A number of

Usman Mustafa is Principal Investigator and SSO, Agricultural Economics Research Unit, Arid Zone Research Institute, Pakistan Agricultural Research Council, Agricultural Research Institute, Sariab, Quetta. P. L. Pingali is Programme Leader, Irrigated Rice Eco-systems, International Rice Research Institute, Manila, Philippines. 
studies [Cory (1982); Weaver (1984); Bhuiyan (1985); and Chaudhry and Ali (1989)] have indicated that inefficiencies of the irrigation system are mostly due to faulty design and construction, poor maintenance, and mismanagement. Outlets and control structures are either broken or altered while the distribution channels have become silted. In many cases, funds for proper maintenance of the system are inadequate due to low payment of irrigation fees or inadequate allocation system by water agencies, leading to the deterioration of the performance capacity of the system. In addition, mis-allocation and wasteful use of water has contributed to the system's inefficiency. Only a small fraction of the water diverted in most large surface systems in developing countries is available for plant use, typically 25 to 30 percent, as compared to 60 to 70 percent in advanced systems [Rangley (1985)]. One of the major problems in agriculture has been the inefficiency of water use. Even though water availability in Pakistan has increased substantially over the years, there are substantial canal water losses. It is estimated that the present system efficiency is only 45 percent [Government of Pakistan (1988)]. Estimates of the seepage losses in main canals, branch canals, and distributaries range between 900 and 4500 litres/sec/million square metres [Kijne (1989)]:

Intensification and mismanagement of surface irrigation system led to low efficiency but, more importantly, it also brought in its wake the serious and complicated problems of waterlogging and salinity, leading to the degradation of land resources [Pinstrup-Anderson and Pandya-Lorch (1994)]. Some direct effects include crop substitution and a decline in crop production and farm income. It could also worsen unemployment, migration, regional disparity, deterioration of natural resources, and ecological balance, etc. [Joshi (1987)].

The adverse effects of long-term canal irrigation in Pakistan (i.e., waterlogging and salinity) are well-documented, although salinity problems in the Indus Basin are not entirely associated with irrigation. Waterlogging and salinity are particularly acute in Sindh and Punjab, the granaries of Pakistan: in Sindh, about half of the soils are saline, of which 18 percent are strongly saline. According to an estimate by the Government of Pakistan, almost one-tenth of the country's best agricultural land is affected by salinity [Government of Pakistan (1989) and Khan (1991)]. Soil studies of the Indus Basin have revealed that most soil salinity is very old, produced in the process of soil formation long before the introduction of canal irrigation. Salinity has adversely affected the physical and chemical characteristics of the soils to considerable depths. Undoubtedly, secondary salinity associated with a high watertable resulting from irrigation has aggravated the problem [Kijne (1989)].

Rice is a highly valued cash crop that earns substantial foreign exchange for the country. Presently, rice is grown in more than two million hectares with almost four million tonnes of production [Government of Pakistan (1994)]. There is increasing evidence that the growth in rice yield has slowed down, and there is 
continued decline in yield growth, especially in the irrigated lowlands of Asia [Pingali, et al. (1990)].

The slow-down in rice productivity growth in Asia since 1980s has been caused by: (a) the world rice price-induced factor and (b) the intensification-induced factor. The long-term decline in the world rice price has resulted in reduced investments for irrigation infrastructure (causing land degradation ) and rice research [Rosegrant and Pingali (1991)]. Land degradation and rice are of great concern to planner and policy-makers. Considerable experimental work has been carried out regarding the effect of salt-affected soils on the quality of rice yield, but relatively few empirical studies on the subject have been reported, particularly on Pakistan. The objective of this study is to examine empirical inter-relationships between land degradation and irrigated rice hectarage in Pakistan's Punjab province. Quantitative assessment of these parameters provides the necessary insights when developing strategies to control land degradation and to increase the rice yields under surface irrigation system.

\section{METHODOLOGY}

Land degradation is a broad term. For the present study, its specific area is defined below and the theoretical part of the model is explained before elaborating the methodology/model.

\section{Land Degradation}

Land degradation caused only by the water- and fertiliser-intensive agriculture (secondary salinity) was studied. The major causes and negative effects of surface irrigation and its mismanagement were also studied. These are: problems of soil salinity/alkalinity and waterlogging. Thus, before the introduction of irrigation into an area, there exists a water balance between the rainfall on the one hand and evaporation and transpiration on the other. This balance is disturbed with the mismanagement of surface irrigation including poor drainage, in an area of high seepage, from unlined canals and distributaries, all of which results in disturbing the water balanice and in a rising water-table. The rise in water-table is due to the water supplied by surface irrigation over and above the quantities utilised by the crops. The groundwater does not have a sizeable concentration of harmful salts, so this will result in waterlogging without salinity.

Once the groundwater table is close to the soil surface, appreciable upward movement of the groundwater due to evaporation from the soil surface (through capillary actions) takes place and results in the accumulation of salts in the root zone, which causes salinity.

Sometimes, salinity and waterlogging appear together, when groundwater comes near the root zone, and also have a high concentration of salts. It could also 
appear independently of any occurrence of waterlogging, accentuated by a high level of fertiliser use [Karanth (1986)]. There is also increasing evidence of very high levels of salinity in areas of groundwater irrigation due to over-exploitation or continued use of brackish underground irrigation water. It is not, therefore, easy to determine when and whether salinity results from waterlogging. Because of this, we define waterlogging and salinity together as elements of land degradation and do not make an attempt to divide the total into its two component parts. The crux of the problem appears to be a distortion of the natural equilibrium between groundwater discharge and recharge [Chopra (1989)].

The maintenance of agricultural productivity depends, among other things, on the soil water balance. These soil water-balance equations imply, in essence, that the rise and fall of the water-table depends on: (a) specific yield (volume of water released or stored per unit surface area of the aquifer per unit change in the component of the head normal to that surface), a property of the aquifer and the textural and structural characteristics of the soil; (b) precipitation or rainfall; (c) volume of irrigation water delivered to the fields; (d) volume of water discharged at the land surface; (e) evaporation from land surface and in the zone of aeration respectively; and (f) increments in water storage at land surface and in the zone of aeration respectively. Each of these components has to be monitored in planning for an efficient use of water.

\section{Time Series Model for Land Degradation}

A simplified model is developed for land degradation. Land degradation depends on factors affecting the water-balance equation, and also on continuous fertiliser application [Karanth (1986)]. Rice hectarage is determined by land degradation and other variables; expected tubewells; expected rainfall during the rice-planting season; expected prices of rice and alternative crops; and district dummy for Punjab, province of Pakistan. Before explaining the specification of the land degradation model, the study area for this model is elaborated. The time series study was analysed in the Faisalabad and Gujranwala districts of Punjab province of Pakistan. Both districts are situated in semi-arid to sub-humid tropical continental lowland known as Zone II. These districts are also situated in the Rechana Doab Irrigation System. Gujranwala district is famous for rice-wheat growing, whereas Faisalabad district has a mixed cropping system. Both districts are affected by land degradation (Figures 1 and 2).

\section{Specification of the Model}

Land degradation affects area under different crops along with other factors. The model for rice area function is given as follows:

$$
P R O R A T_{t}=f\left(P R I C E R_{t}^{*}, P R I C E C_{i}^{*}, T W T C_{t}^{*}, R A I N K_{t}^{*}, L D_{t}, D D, v\right) \quad \ldots
$$




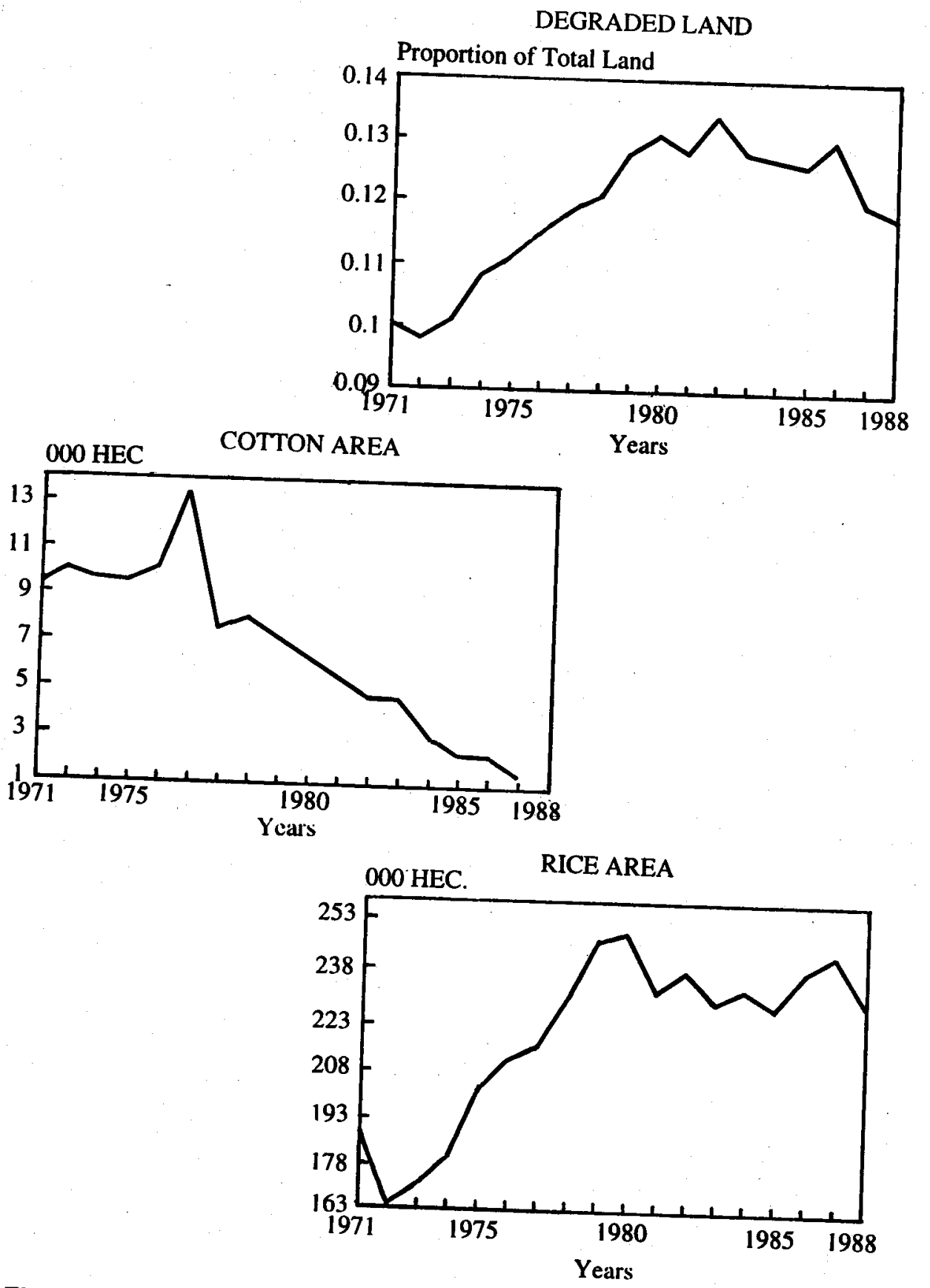

Fig. 1. Land Degradation, Cotton and Rice Hectarage in Gujranwala District. 


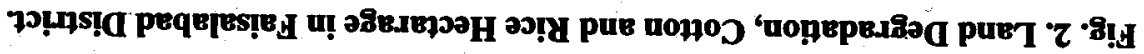
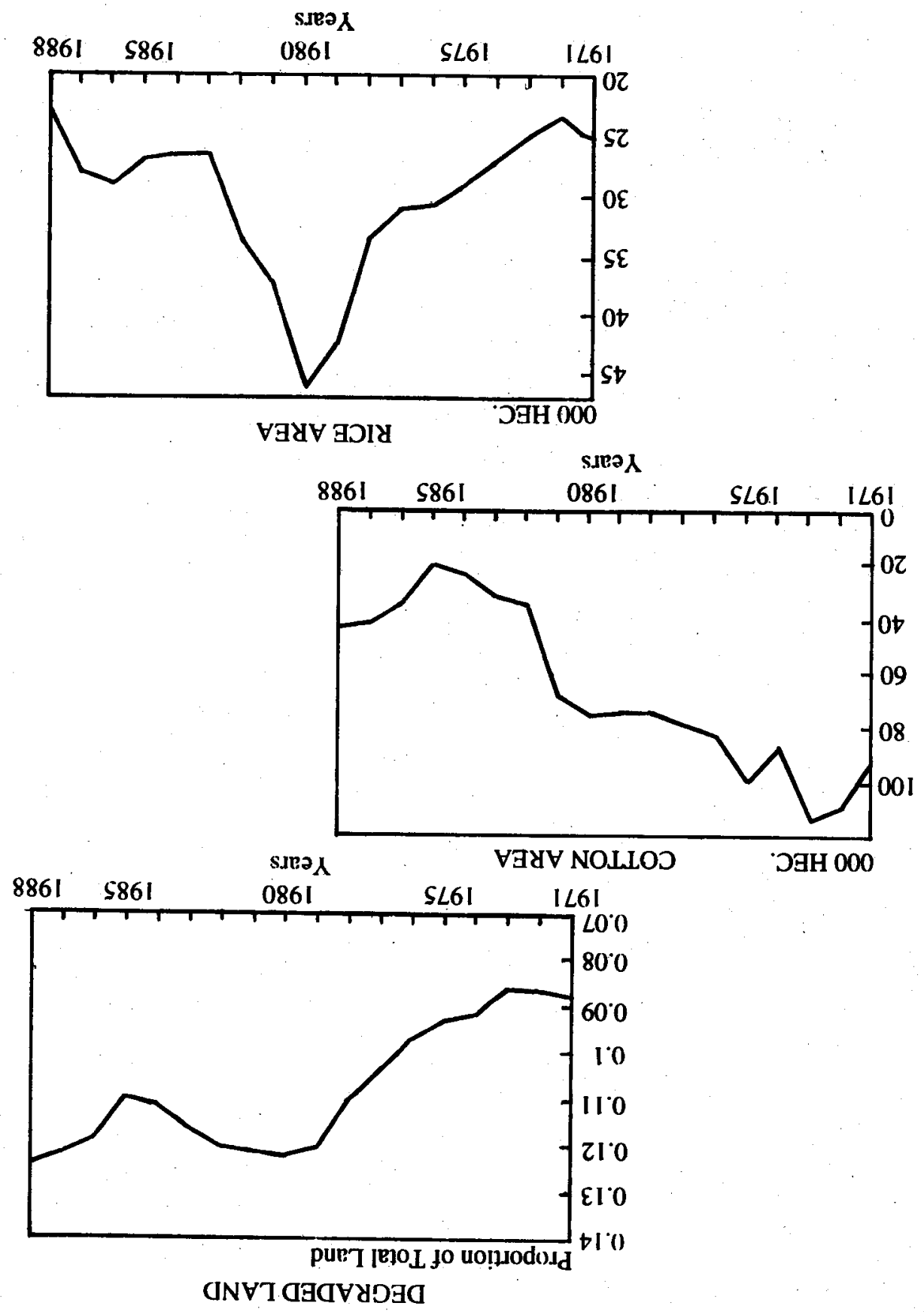
Where the proportion of rice area $\left(P R O R A T_{y}\right)$ depends on price of rice $\left(\right.$ PRICER $\left._{t}^{*}\right)$ and alternative crop $\left(P R I C E C_{t}{ }^{*}\right)$, tubewells $\left(T W T C_{t}{ }^{*}\right)$, rainfall during rice-planting season $\left(R A I N K_{t}^{*}\right)$, land degradation $\left(L D_{t}\right)$, district dummy $(D D)$, and error term $v$. $t$ is time period (1971-88), and * represents the expected values.

Land degradation $(L D)$ is not an exogenous variable in Equation 1. It is further hypothesised to depend on canal water withdrawal $\left(C A N W_{t}\right), T W T C_{t}{ }^{*}$, annual rainfall $\left(R A I N T_{t}^{*}\right)$, level of fertiliser use $\left(N P K C_{t}\right)$ and $D D$. Land degradation model can be specified as follows:

$$
L D_{t}=f\left(C A N W_{t}, T W T C_{t}, R A I N T_{t}, N P K C_{t}, D D, u\right) \ldots \quad \ldots \quad \ldots
$$

In the above equations, there is a joint dependence between PRORAT and $L D$, their relationship cannot be described with a single equation, but with a system of simultaneous equations. In each relation, there are explanatory variables which are endogenous to the system, that is, they appear as dependent in other equations of the system. Thus, for any particular equation, the random variable is not independent of the explanatory variable(s). Since the application of ordinary least squares (OLS) to an equation belonging to a system of simultaneous equations yields biased and inconsistent estimates, the obvious solution is to apply other methods of estimation which give better estimates of the parameters.

Two conditions must be met to ensure that a simultaneous-equation model is identified, i.e., a unique set of parameter estimates must exist. They are the order and rank conditions [Kamenta (1971)].

Three-stage least squares (3SLS) is a systems method, which is applied to all the equations of the model at the same time and gives estimates of all the parameters simultaneously. This method was developed by Theil and Zellner as a logical extension of Theil's 2SLS [Zellner and Theil (1962)]. It involves the application of the method of least squares in three successive stages. It utilises more information than the single-equation techniques, that is, it takes into account the entire structure of the model with all the restrictions that this structure imposes on the values of the parameters.

Three-stage (3SLS) least-squares is an efficient technique to solve a system of equations that is over-identified. The three-stage least-squares technique is superior as it generates consistent and efficient parameter estimates when the disturbance terms $(u, v)$ of the structural equations are dependent, which is the case with the present model [Koutsoyiannis (1977)]. Thus 3SLS was used to simultaneously solve the land degradation and proportion of rice hectare equation model.

In the above equations we used the expected variables for prices. There are different ways of estimating the expected variables and prices. Many researchers, beginning with Nerlove, have inserted more realistic formulations into the supply analyses extending over a period of time. The main problem of attaching weights in a 
series is that it does not isolate the stationary and random effects. Secondly, in most cases, the weights are assigned without any empirical basis. The decision rule about expectation is, therefore, heavily based on the researchers' subjective assessment [Ali (1990)].

The Univariate Box and Jenkins (UBJ) Autocoregressive Integrated Moving Average (ARIMA) model was applied in this study to estimate the expected variable. The UBJ approach has advantages over many other traditional single series methods [Pankratz (1983)]. ARIMA models also have the flexibility to forecast the value of a variable by being able to identify separately the stationary and random components of each of its values [Box and Jenkins (1976)]. Among various ARIMA schemes, we selected the best ones based on the criteria suggested by Box and Jenkins. A properly constructed ARIMA model produces an optimal univariate forecast.

Equations 1 and 2 were estimated in semilogrithm form as follows:

$$
L D=a_{0}+a_{1} \mathrm{LCANW}+a_{2} L R A I N T+a_{3} T W T C+a_{4} N P K C+a_{5} D D+u
$$

and

$$
\begin{aligned}
& \text { PRORAT }=b_{0}+b_{1} L D+b_{2} \text { LRAINK }^{*}+b_{3} \text { TWTC }^{*}+b_{4} \text { PRICER }^{*} \\
& +b_{5} \text { PRICEC }^{*}+b_{6} D D+\nu \ldots \quad \ldots \quad \ldots . \quad \ldots \quad \ldots
\end{aligned}
$$

The expected price of rice $\left(P R I C E R^{*}\right)$ is a more relevant variable for the proportion of rice area function. The price of rice is deflated with the nitrogen fertiliser price. Consistent with economic theory, the expected price is hypothesised to have positive effects on the rice area function.

Another economic force that influences the farmer in allocating the area planted with rice is the expected price of alternative crop, say "cotton" $\left(P R I C E C^{*}\right)$. They also consider the possible profit that they can earn from the same piece of land by planting other crops. Other things remaining the same, if the price of rice is relatively higher than that of alternative crops, then the farmers will tend to allocate more land area to rice production. In the present study, we include cotton as an alternative competing crop. As indicated by Ali (1990), cotton strongly competes with rice. The expected price of cotton is expected to be negative for rice area. $b_{0}, b_{1}$, $b_{3}, \ldots$ are the constants while all the other variable are defined in Table 1. The major source of data in the present study is from the International Waterlogging and Salinity Research Institute [IWSRI (1988)] and other Government sources.

\section{RESULTS AND DISCUSSION}

In order to understand the general situation in the study area, an overview of land degradation and rice and alternative crop area are analysed. Figures 1 and 2 show the land degradation and rice and cotton hectarage in Faisalabad and Gujranwala 


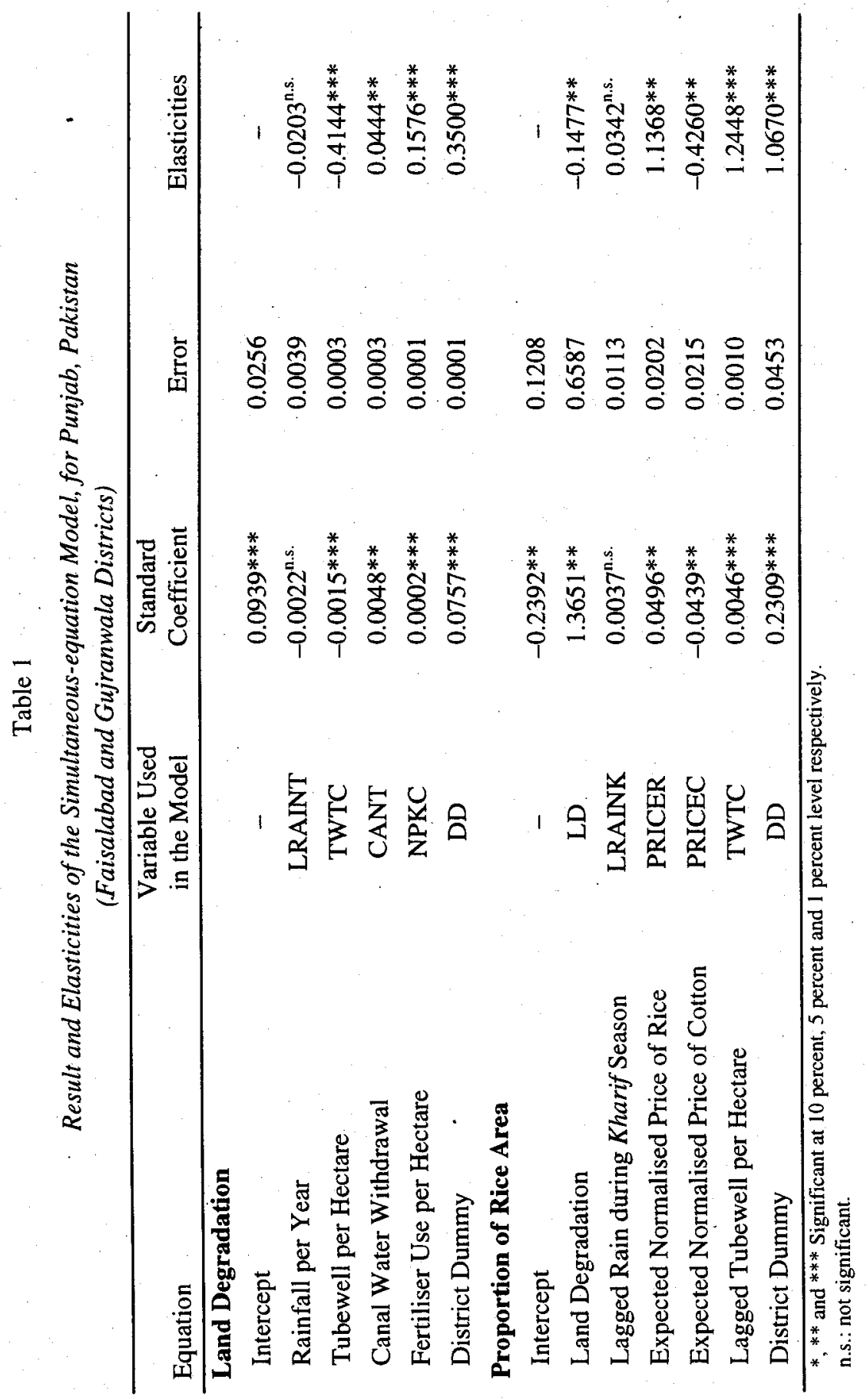


districts. Rice hectarage is positively related with land degradation whereas the cotton area exhibited a negative response with respect to land degradation. This relationship is very clear up to 1981 but in recent years there is really no clear relationship with land degradation, especially in Faisalabad district. Severe insect infestation in 1980 significantly affected rice hectarage, as shown by the decrease in rice area cultivation. In case of Gujranwala district, cotton area continuously decreased. It is important to know that cotton is not a major crop in either district. Cotton is a deep-rooted crop. It can tolerate salinity and waterlogging to some extent, but beyond a certain level it suffers from diseases and low productivity due to delay and poor seed formation [Mayora (1988); Jafri and Ahmad (1990)].

ARIMA model produces the optimal univariate forecast. For the ARIMA procedure, price data of nitrogen fertiliser, rice and cotton are the same as in Tweeten's (1985) study. Prices are updated since Tweeten's (1985) study up to 1988. Although the study primarily used time series data from 1971 to 1988 in the price expectation, function data since 1957 were used (other data were only available from 1971). This increased the size of observation, and provided better and precise results. Expected values were very close to actual values. This increased the validity of the model in addition to the significance of statistical tests.

\section{Land Degradation and Proportion of Rice Area}

Land degradation and proportion of rice area function equations were simultaneously used. The 3SLS estimates of the model were derived using SASSYSREG [Statistical Analysis System (1979)]. Results of the model are reasonably acceptable. All the explanatory variables appear with expected signs except the total rainfall $(R A I N T)$. Canal water withdrawal $(L C A N W)$ was significant at 5 percent level, whereas fertiliser use $(N P K C)$, tubewells (TWTC), and district dummy $(D D)$ were significant at 1 percent level. Rainfall per year (LRAINT) was not significant. The results are presented in Table 1.

In the model the proportional rice area response function equation also showed very interesting results. All explanatory variables showed the expected signs and were significant, whereas only expected rain during the rice season was not significant. Canal water withdrawal (LCANT) and fertiliser use per hectare (NPKC) tend to induce land degradation due to increases in waterlogging and salinity. In Pakistan, canals are not lined with concrete. There is also poor drainage, and even if there is some drainage, it is not well-maintained. In some places, even the natural drainage has been disturbed.

The adverse effects of long-term canal irrigation in Pakistan (waterlogging and salinity) are well-documented, although salinity problems in the Indus Basin are not entirely associated with irrigation. Results revealed that increasing canal water by 100 percent will increase the dependent variable by 4 percent (Table 1). 
Studies show that, to some extent, the increase in fertiliser use per hectare also leads to land degradation [Joshi (1987); Singh et al. (1987); and Chopra (1989)]. These findings might be surprising, but it is important to note that mismanagement and continuous and increased application of fertiliser have negative effects both on soil structure and natural fertilisation. Fertilisers have a higher p. $\mathrm{H}$ and their intensive use also increased the p.H of soil. Results indicate small (.0002) but significant contribution to land degradation.

Some studies [Wilsdon and Sarathy (1927); Chopra (1989)] reported that rainfall, primarily due to monsoon, raises the water-table and leads to land degradation. The present study has a different result, with rainfall showing a negative sign, but this is not statistically significant. This reveals that rainfall decreases land degradation. This may be true because in the study area annual rainfall is not so high and, in one way, it also helps in leaching the salts.

The positive impact of tubewells on production is well-documented. Tubewells not only increase crop production, and cropping and land use intensities, but also shift the cropping pattern to high-value crops. These also play a very positive and significant role in decreasing land degradation. Results indicate negative and significant coefficients for the tubewell variable. With a hundred percent increase in tubewells, there will be a 4 percent decrease in proportion of land degradation in the study area. The role of brackish tubewell water was not studied, although this also leads to land degradation.

Results of the present study show a positive and highly significant coefficient of tubewells per hectare (TWTC), and increase in rice area which effects land degradation. Rice plantation may lead to an increase in water-table level and, ultimately, land degradation. It is important to note that in rice-growing area, there is also a large concentration of tubewells. Our field survey also shows that the majority of rice-growing farmers use tubewell water along with canal irrigation. Correlation matrix also indicated a high correlation between rice area and tubewells. Research carried out in Pakistan by the International Irrigation Management Institute (IMMI) IMMI (1990) showed that water-tables in the area do not rise during the monsoon season. Apparently, seepage from rice-fields and recharge from the monsoon rains are balanced by withdrawals from the groundwater by tubewells.

Although both districts (Faisalabad and Gujranwala) are in the same rice production zone and irrigation system (the Rechana Chenab Irrigation System), the district dummy was significant at 1 percent level. This indicates that there are some other factors which also contribute in the spread of land degradation but are nin explained by the model.

Land degradation variable, which is an independent variable in Equation (4) but a dependent variable in Equation (1), showed a positive and significant coefficient. This indicates that land degradation has a positive impact on rice 
hectarage. The estimated elasticity of $L D$ was 0.1477 . This means that if there is 100 percent change in land degradation, the proportional rice area will change by 14.77 percent (Table 1). This indicate that land degradation brought more marginal land under rice cultivation. Expected rainfall during rice-planting season (LRAINK*) exhibited a positive but non-significant coefficient. The elasticity of $L R A I N K^{*}$ with respect to the proportional rice area was 0.0037 . This implies that a 10 percent change in rainfall will cause a change in rice area by 0.04 percent. Water is one of the most important factors in rice production. The positive effect of rainfall is understandable because it made available more water for paddy cultivation. There is a highly correlation between availability of irrigation water and rice cultivation.

The $T W T C^{*}$ variable exhibited a positive and significant coefficient at 1 percent level. The elasticity with respect to the $L T W T C^{*}$ was 1.2448 . This implies that a 10 percent change in $L T W P C^{*}$ will bring about 12.45 percent change in rice hectarage.

Two sets of price variables, $\left(P R I C E R^{*}\right)$ and $\left(P R I C E C^{*}\right)$, were used as a separate variable in the proportional rice area response function. These expected prices were developed by adopting the ARIMA technique. Both prices showed the expected sings. Rice price was positive and significant. Rice price elasticity with respect to proportional rice area was 1.1368 . This implies that if there is a 10 percent change in the normalised price of rice, it will result in 11.37 percent change in proportional rice area.

The expected normalised price of cotton $\left(P R I C E C^{*}\right)$ was negative and significant. This indicates that cotton prices are inversely related with rice area. This can be explained because cotton is an alternative crop for rice. Cotton strongly competes with rice, although these are grown in different regions. However, these regions, to some extent, can and have been expanded or contracted according to the relative price situation of the crops [Ali (1990)]. The negative and significant sign of $\left(P R I C E C^{*}\right)$ validates our previous hypothesis that land degradation has a negative effect on cotton hectarage in the study area. It is also important to mention that the study area is not a cotton-growing region. The cotton cultivation may not be economical in rice-growing areas; even the price of cotton increased, but there was a significant decrease in the yield due to land degradation. In fact, if farmers continue growing cotton, they might be the net loosers. It also indicates that rice farmers are more responsive to real price of rice than of the alternative crop. The district dummy $(D D)$ for rice area was significant at 5 percent level.

\section{CONCLUSIONS AND RECOMMENDATIONS}

In an agrarian economy like Pakistan, with its limited endowments and high population growth pressure, land degradation is of particular concern to planners and policy-makers. Canal water withdrawal and fertiliser use tend to induce land 
degradation due to the increase in waterlogging and salinity. Tubewells per hectare (by reducing the water-table) and the rainfall (by washing and leaching surface salts) variables decrease land degradation. The ARIMA model exhibited that the predicted variables are very close to actual variables. This indicates that this technique is very useful and improves the significance of the model.

Rainfall during the rice-planting season brought more area under rice cultivation. Similarly, with more tubewells, more rice cultivation is encouraged because of assured continuous supply of irrigation water for rice production. There was a significant difference among districts. Land degradation also increases rice cultivation because rice is more salt-tolerant than cotton.

In a developing country like Pakistan, where agriculture is the mainstay of the economy, 50 percent of the labour is engaged in agriculture and 75 percent population lives in villages. The menace of land degradation is of great concern. Land degradation not only affects efficient utilisation of scarce resources but also reduces the farmers' and national income.

In a broad sense, this study has shown that land degradation (secondary salinity and waterlogging) had been caused due to a defective and mismanaged surface irrigation system. Inefficient use-of costly inputs like land and fertiliser aggravate this problem. Special attention should be given to water conservation. There is a need to increase the declining public irrigation investment for its improvement and efficient utilisation. This can be done by lining the main canals and branches as a water conservation measure, but it is very expensive. It is better to start with a low-cost water course improvement programme; the optimum lining length should be greatly accelerated and made more cost-effective.

Lining of minors and distribution water channels should be taken up as a priority in those areas where there is high seepage and which are located in the saline groundwater region. The natural drainage system was heavily disturbed by the introduction of the infrastructure for irrigation and drainage, as well as that for transport by rail and road. There is a need for establishing an effective and wellplanned surface drainage system for the expeditious removal of all excess surface water from precipitation, irrigation, and flooding.

Tubewell installation should be limited to the best groundwater area. If the farmers are encouraged to play an active role in the installation of private tubewells, the programme would cost drastically less and achieve a great deal more. If the groundwater is saline, then the utilisation of the water will be a problem because saline water will spread more salinity.

There is a need to evaluate the irrigation system performance and the optimal ratios of saline and non-saline irrigation water for crop production. There is also a need for an efficient and well-balanced utilisation of expensive fertiliser. Proper amelioration of these soils can be effected quickly and economically by using gypsum. 


\section{REFERENCES}

Ali, M. (1990) Estimating the Supply Response of Major Crops in Pakistan Using a Simultaneous Equation Approach. The Pakistan Development Review 29:3\&4 305-325.

Bhuiyan, S. I. (1985) Irrigation Technology for Food Production: Expectations and Realities in Southeast Asia. Paper presented at the conference on Water and Water Policy in World Food Supply, Texas A\&M University, U.S.A., May 2630, $11 \mathrm{pp}$.

Box, G. E. P., and D. G. M. Jenkins (1976) Time Series Analysis. San Francisco: Holden-Day.

Chaudhry, M. A., and M. Ali (1989) Economics of Past and Prospective O\&M Investments in Different Components of the Irrigation System in Pakistan's Punjab. ODI-IIMI, Irrigation Management Network Paper 89/1d, June.

Chopra, K. (1989) Land Degradation: Dimension and Causalities. Indian Journal of Agricultural Economics 44:1 45-54.

Cory, A. T. (1982) Unpublished Report on Water Management on Sri Lanka. Agrarian Research Training Institute, Colombo, Sri Lanka.

Pakistan, Government of (1988) Report of the National Commission on Agriculture. Islamabad: Ministry of Food and Agriculture.

Pakistan, Government of (1989) National Conservation Strategy. Islamabad: Environment and Urban Affair Division.

Pakistan, Government of (1993) Report of Prime Minister's Task Force on Agriculture. Islamabad: Revenue Division. Ministry of Finance, Revenue and Economic Affair.

Pakistan, Government of (1994) Economic Survey 1993-94. Islamabad: Finance Division, Economic Adviser's Wing.

IMMI (1990) Annual Report. Colombo, Sri Lanka: International Irrigation Management Institute.

IWASRI (1988) Data Release on Various Aspects of Waterlogging and Salinity in Rechana Doab (Punjab). International Waterlogging and Salinity Research Institute, WAPDA, Lahore.

Jafari, A. Z., and A. Rafiq (1990) Effects of Different Levels of Soil Salinity on Reproductive Physiology and Yield of Cotton Plants. Paper presented at IndoPak Workshop on Soil Salinity and Water Management, organised by PARC, Islamabad, in collaboration with IWASRI, Lahore, February 10-14.

John Mellor Associates, Inc. (1993) Institutional Reforms to Accelerate Irrigation Agriculture and Asianics Agro-Dev. International (Pvt.) Ltd., Islamabad. Washington, D. C. and Islamabad: Pangraphics.

Joshi, P. K. (1987) Effect of Surface Irrigation on Land Degradation Problem and Strategies. Indian Journal of Agricultural Economics 42:3. 
Karanth, K. R. (1986) Waterlogging: Causes, Prevention and Control: In Central Ground Water Board (1986): Proceedings of the Seminar on Conjunctive Use of Surface and Ground Water. Ministry of Water Resources, Government of India, New Delhi.

Khan, Fazle Karim (1991) A Geography of Pakistan: Environment, People, and Economy. Karachi: Oxford University Press.

Kijne, J. W. (1989) Irrigation Management in Relation to Waterlogging and Salinity.

International Irrigation Management Institute (IIMI), Country Paper-Pakistan

No. 2. Colombo, Sri Lanka.

Kmenta, J. (1971) Elements of Econometrics. New York: Macmillan.

Koutsoyiannis, A. (1977) Theory of Econometrics. (Second Edition). London: The Macmillan Press Ltd.

Mayora, M. I. (1988) Economic Impacts of Salinisation in Irrigated Agricultural

Land: An Arizona Case Study. Unpublished Ph. D. dissertation, School of Renewable Natural Resources, The University of Arizona.

Pankratz, A. (1983) Forecasting with Univariate Box-Jenkins Models Concepts and Cases. New York: John Willy and Sons.

Pinstrup-Anderson P., and R. Pandya-Lorch (1994) Poverty, Agricultural Intensification, and the Environment. The Pakistan Development Review 33:4 463-496.

Pingali, P. L., P. F. Moya, and L. E. Verasco (1990) The Post-green Revolution Blues in Asian Rice Production-the Diminished Gap between Experiment

Station and Farmer Yields. Social Sciences Division. Los Banos, Philippines:

International Rice Research Institute. (Paper No. 90-01.)

Qureshi, S. K., and Zakir Hussain (1994) An Assessment of Warabandi (Irrigation

Rotation) in Pakistan: A Preliminary Analysis. The Pakistan Development

Review 33:4 845-855.

Rangley, R. (1985) Irrigation and Drainage in the World. Paper presented at the seminar on Water and Water Policy in World Food Supply, Texas A \& M University, USA.

Rosegrant, M. W., and P. L. Pingali (1991) Sustaining Rice Productivity Growth in Asia: A Policy Perspective. Social Science Division. Los Banos, Philippines: International Rice Research Institute. (Paper No. 91-01.)

Singh, I. P., Bijay S., and H. S. Pal (1987) Indiscriminate Fertiliser Use vis-à-vis

Groundwater Pollution in Central Punjab. Indian Journal of Agricultural Economics 42:3, July-September.

Statistical Analysis System (1979) SAS User's Guide. (2nd Ed.) SAS Institute, Inc. Cary, NC, $376 \mathrm{pp}$.

Tweeten, L. (1985) Supply Response in Pakistan. Report prepared by Department of Agricultural Economics, Oklahoma State University and Abt Associates, Inc. 
Under contract No. DAN-4084-c-00-3-87-00. Agricultural Policy Analysis Project, US AID, Washington, D. C.

Wilsdon, B. H., and R. P. Sarathy (1927) Memoirs, Punjab Irrigation Research. 1:1. Lahore.

Weaver, T. F. (1984) Problem Area and Researchable Issues in Irrigation. Workshop on Research Priorities for Irrigation Management in Asia. Los Banos, Laguna, Philippines: International Research Institute.

Zellner, A., and H. Theil (1962) Three-stage Least Squares: Simultaneous Estimation of Simultaneous Equations. Econometrica 30: 54-78. 


\section{Comments}

The title of the paper suggests a very important and interesting study of a very serious problem facing the agriculture sector in Pakistan. However, the paper leaves much to be desired. The structure of the paper is disjointed and confusing, and the model used is a recursive model whereas the authors claim it to be a simultaneous model.

The section on methodology is a misnomer, because it does not present any methodology; rather, it contains a discussion related to soil-water balance equations. However, these equations are not found in the paper. It seems that these have been taken from another study, but there is no reference to it.

Under the sub-title "Time Series Model for Land Degradation," the determinants of rice acreage include other variables. These other variables are neither defined nor tested. These other variables may include technical change like better seeds, chemical fertilisers, better sowing or harvesting techniques, etc.

Under this model all the variables in the first equation are marked with asterisks $(*)$ and referred to as expected variables. Later on, the paper refers to the use of ARIMA model to estimate the expected variables. But how ARIMA has been used to estimate expected values of the existing data is not very clear.

As stated earlier, the model is a recursive model rather than simultaneous as claimed by the authors. If it is a simultaneous model, where is the PRORAT variable in Equations 2 and 3 ?

Two sets of results are reported in this paper. The first set of results on Page $9^{*}$ refers to two figures ( 1 and 2). Figure 2 pertains to Faisalabad District and the authors report a negative relationships between cotton and land degradation until 1981, beyond which they say there is no clear relationship. However, if we look carefully at Figure 2, the middle graph quite clearly shows the declining relationship upto Year 1985, and beyond that it becomes positive. Similarly, in Graph 3 (Figure 2), after 1981 there is a sharp decline in the association between rice area and land degradation, and it remains constant followed by a slight increase. Then it starts to decline again. There is no conclusion to these results; only the movements in two figures are vaguely explained.

The results of the equations are explained on Page 10. The authors report the significance and non-significance of the variables. On Page 11, the authors refer to Table 2, but this table is not found in the paper. On Page 12, the authors state that IMMI (1990) has shown that water-tables do not rise in these areas in the monsoons because the water-table is not very high, and also that in these areas the rainfall is not

"The page numbers referred to here are those of the original version presented at the 11 th Annual General Meeting. 
very high. Furthermore, seepage from rice fields and the recharge from monsoon rains are balanced by withdrawal of water by tubewells. They also state that the significance of dummy variable indicates that there are other factors responsible for land degradation which are not explained by the model.

Now if the water-table is not high in these areas, rainfall is not high, tubewells are doing the job, and dummy variable refers to other variables not captured by the model (earlier on Page 6 the dummy variable is defined as district dummies for the Punjab province), one wonders what the study is about?

Secondly, while PRORAT equations do not include any lagged variable results for rain and tubewells, Table 1 reports results for lagged variables.

On Pages 13 and 14, cotton is described as an alternative crop to rice, while on Page 10 it is described as "not a major crop in either district". Similarly, on Page 14. Gujranwala District is reported to be "more famous for rice-wheat cropping system", and for Faisalabad it is said that "besides rice-wheat, other crops are also grown extensively". The authors do not really justify the cotton-rice pairing in this study despite such statements.

The results of Table 1 show very low coefficients for the so-called 3-stage least squares model. Did the authors first try OLS? Were the results inferior to this and hence dumped? If not so, perhaps it would be useful to proceed more systematically and try both OLS and OLS with IVs and then decide on the use of the simultaneous model. Also reconsider the relevant variables included and excluded here in light of the discussion in the paper - to remove the contradictions and to clarify the policy implications of such an important study.

Pakistan Institute of

Faiz Bilquees

Development Economics,

Islamabad. 